\title{
The hypoxic microenvironment upgrades stem-like properties of ovarian cancer cells
}

\author{
Dongming Liang ${ }^{1 \dagger}$, Yuanyuan Ma ${ }^{1,3+}{ }^{+}$, Jian Liu ${ }^{5}$, Claes Goran Trope ${ }^{2,4}$, Ruth Holm³ \\ Jahn M Nesland ${ }^{1,3}$ and Zhenhe Suo ${ }^{1,3^{*}}$
}

\begin{abstract}
Background: To study whether hypoxia influences the stem-like properties of ovarian cancer cells and their biological behavior under hypoxia.

Method: Ovarian cancer cell lines ES-2 and OVCAR-3 were cultivated in different oxygen tensions for proliferation, cell cycling and invasion analyses. The clonogenic potential of cells was examined by colony formation and sphere formation assays. Stem cell surface markers, SP and CD 44 $4^{\text {bright }}$ and CD44 ${ }^{\text {dim }}$ cells were analyzed by flow cytometry. Protein expression of HIF-1a, HIF-2a, Ot3/4 and Sox2 were investigated by Western blotting.
\end{abstract}

Results: Both cell lines cultivated at hypoxic condition grew relatively slowly with extended G0/G1 phase. However, if the cells were pre-treated under $1 \% \mathrm{O}_{2}$ for 48 hrs before brought back to normoxia, the cells showed significantly higher proliferation rate with higher infiltration capability, and significant more colonies and spheres, in comparison to the cells always cultivated under normoxia. CD44 ${ }^{\text {bright }}$ cells expressed significantly higher levels of Oct3/4 and Sox2 than the CD44 ${ }^{\text {dim }}$ cells and formed significantly more clones and spheres examined in vitro. Hypoxic treatment of the cells resulted in stronger CD44 expression in both cell lines, and stronger CD133 expression in the OVCAR-3 cell line. In parallel with these findings, significantly increased number of side population (SP) cells and up-regulated expression of Oct3/4 and Sox2 in both ES-2 and OVCAR-3 cell lines were observed.

Conclusion: We conclude that ovarian cancer cells survive hypoxia by upgrading their stem-like properties through up-regulation of stemness-related factors and behave more aggressively when brought back to higher oxygen environment.

\section{Background}

Hypoxic microenvironments are frequently found in many solid tumors including breast cancer, prostate cancer, brain tumor, malignant melanomas, metastatic liver cancer and ovarian cancer [1-5]. Solid tumors frequently encounter hypoxic stress. Rapidly proliferating cancer cells may outgrow their vascular network and limiting $\mathrm{O}_{2}$ diffusion within the tumors. Hypoxic stress can also be caused by perfusion defects as a result of abnormal tumor blood vessel structure and function [6]. Hypoxia not only accounts for tissue

\footnotetext{
* Correspondence: zhenhes@medisin.uio.no

${ }^{\dagger}$ Equal contributors

'Departments of Pathology, the Norwegian Radium Hospital, Oslo University Hospital, University of Oslo, Montebello, Ullernchausseen 70, N-0310 Oslo, Norway

${ }^{3}$ Departments of Pathology, Institute for Clinical Medicine, Faculty of Medicine, University of Oslo, Montebello, Ullernchausseen 70, N-0310 Oslo, Norway

Full list of author information is available at the end of the article
}

necrosis but also has a strong impact on tumor cell biology, with a decreased sensitivity to apoptotic and other cell-death signals, and increased signaling to promote angiogenesis, proliferation and systemic metastasis capacity [7]. Tumor hypoxia is not only a major problem for radiation therapy, but it has also been implicated in the development of resistance to many conventional chemotherapeutic agents $[8,9]$. The cancer stem cells particularly have been demonstrated to escape from the radiotherapy and chemotherapy and are able to form metastatic tumor in other organs. Several somatic tumors including ovarian tumors are considered to contain a small subset of stem-like cells called cancer stem cells, which have the capacity to self-renewal, differentiate and initiate new tumor [10-17].

The hypoxia inducible factors (HIFs) can be regulated by oxygen availability. HIFs are recognized as key modulators of the transcriptional response to hypoxic stress. Besides its adaptive function in cellular stress responses, recent work

\section{Biomed Central}


has also revealed important roles for HIFs in both physiological and pathological processes [6]. Increasing evidence indicates that HIFs regulate a number of genes including glucose metabolism, cell survival, erythropoiesis, stem cell maintenance, angiogenesis related markers and resistance to chemotherapy and radiation therapy [18]. Embryonic stem cell markers, the transcription factors Oct $3 / 4$ (also called POU5F1) and Sox2 have a pivotal role in the maintenance of self-renewal of embryonic stem cells and primordial germ cells. Oct $3 / 4$ is a homeodomain transcription factor of the POU family. Some laboratories found that the expression of Oct $3 / 4$ and Sox 2 has an important role in cancer cells survival, self-renew, differentiation and proliferation in different somatic tumors such as lung, gastric, colorectal, rectal, bladder, breast, prostate and ovarian cancers [19-21].

In addition, cancer stem cells typically represent a small number of the total tumor cells which can be enriched on the basis of cell surface maker expression. Several surface markers have been reported to be associated with cancer stem-like or progenitor cells. In the ovarian cancer, the early progenitor cells are associated with some specific surface markers like CD44, CD133 and CD117 [22-26]. However, $\mathrm{CD}_{4} 4^{+}$and $\mathrm{CD}_{133^{+}}$subpopulations in ovarian cancer was believed to be heterogeneous and consisted of progenitor cells and differentiated cells as well [24,27].

Previously, SP cells have been found with some properties of cancer stem cells $[28,29]$ and cancer stem cells also express ATP-binding cassette glycoprotein transporters on their surface. These transporters effectively pump out vital dyes, resulting in a characteristic unlabeled side population of cells detected in fluorescence activated cell sorting FACS plot.

The effect of hypoxia on the cancer stem-like characteristics of ovarian cancer cells has not been fully elucidated. Therefore, the aim of this study was to examine whether hypoxia can influence stem-like properties of ovarian cancer cell lines in vitro with the methods of proliferation assay, cell cycle analysis, infiltration assay, colony formation assay, sphere formation assay, SP, FACS and Western blotting. It was repeatedly shown that ovarian cancer cell lines OVCAR-3 and ES-2 under hypoxia exhibit significantly higher levels of stem-like features in vitro.

\section{Materials and methods}

\section{Cell lines and cell cultures}

Human ovarian cancer cell lines ES-2 and OVCAR-3 were purchased from American Type Culture Collection (ATCC, Manassas, VA, USA) and maintained in our lab for this study. For conventional cell culture, $2 \times 10^{5}$ cells were seeded in $25 \mathrm{~cm}^{2}$ culture flasks and maintained in RPMI 1640 medium (Invitrogen, Carlsbad, CA, USA) supplemented with 10\% fetal bovine serum (Invitrogen) and 100units/ml penicillin and
$100 \mu \mathrm{g} / \mathrm{ml}$ streptomycin in a humidified $5 \% \mathrm{CO}_{2}$ incubators at $37^{\circ} \mathrm{C}$.

\section{Hypoxic cell cultures}

The Xvivo Closed Incubation System (XVIVO system $300 \mathrm{C}$, Biospherix, USA) was used in this study to obtain accurate oxygen tensions in different incubators. After $24 \mathrm{hrs}$ cultivation in conventional cell culture (allowing cells to attach onto the flasks), the cells were transferred into different chambers with different oxygen controls for variable period of culture before the cells were harvested for additional examinations including MTT, sphere and colony formation assays, cell cycle analyses, flow cytometry analyses, Western blotting, SP and FACS.

\section{MTT assay}

For evaluation of hypoxia influence on proliferation of cells, 2000 cells/well in $180 \mu \mathrm{l}$ of complete RPMI-1640 medium were seeded into 96-well microplates under either normoxic $\left(20 \% \mathrm{O}_{2}\right)$ or hypoxic $\left(1 \% \mathrm{O}_{2}\right)$ conditions for variable time periods of culture before MTT analyses. In addition, to study whether hypoxia pretreatment influences the proliferation of cells differently, the cells were firstly pretreated under normoxic $\left(20 \% \mathrm{O}_{2}\right)$ or hypoxic $\left(1 \% \mathrm{O}_{2}\right)$ condition for $48 \mathrm{hrs}$ before the cells were re-harvested and then cultured under normoxia for periods of times before MTT assay. After the cells in culture reached their time schedule, $5 \mathrm{mg} / \mathrm{ml}$ of 3-(4, 5-dimethylthiazol-2-yl)-2, 5-diphenyltetrazolium bromides (MTT, Sigma-Aldrich, St. Louis, MO;USA) was added and incubated at $37{ }^{\circ} \mathrm{C}$ for $4 \mathrm{hrs}$ before $150 \mu \mathrm{L}$ of dimethyl sulfoxide (DMSO) (Sigma-Aldrich) was added to each well and mixed thoroughly. The plates were then shaken for $15 \mathrm{~min}$ and absorbance was determined using a spectrophotometer at a wavelength of $490 \mathrm{~nm}$ ( $\mu$ Quant; Bio-Tek Instruments, Winooski, VT,USA).

\section{Cell cycle analysis}

Cells were cultivated under hypoxia or normoxia for $48 \mathrm{hrs,}$ and then harvested into $15 \mathrm{ml}$ sterile conicaltubes, centrifuged and washed with ice-cold PBS. After cell counting, $1 \times 10^{6}$ cells were fixed in $70 \%$ ethanol for 24 hrs at $-20^{\circ} \mathrm{C}$, washed with cold PBS and re-suspended in PBS buffer containing $50 \mu \mathrm{g} / \mathrm{ml}$ of PI and 100 units $/ \mathrm{ml}$ of RNase type A. The cells were then incubated in dark for $30 \mathrm{~min}$ at room temperature. Samples were filtered using a $70 \mu \mathrm{m}$ nylon membrane and analyzed with an LSRII flow cytometer (Becton Dickinson, San Jose, CA, USA) after gating was optimized. Data were analyzed with the FlowJo software (Version 7.6).

\section{Invasion assay}

The invasion assay was performed with 24-transwell chambers (Costar, Bodenheim, Germany), as previously described [30]. Briefly, $1 \times 10^{4}$ cells were harvested and re-suspended in 
$200 \mu \mathrm{l}$ RPMI-1640 medium without serum before plated in the top chamber. The lower chamber of the transwell was filled with $500 \mu \mathrm{l}$ RPMI-1640 medium supplemented with $10 \%$ fetal bovine serum. The cell suspension was applied onto the matrigel membrane and incubated at $37{ }^{\circ} \mathrm{C}$ for 24 hrs. The cells migrated through the matrigel and the filter were fixed with $70 \%$ methanol, stained with $0.2 \%$ crystal violet, washed with $\mathrm{ddH}_{2} \mathrm{O}$ and counted under microscopy.

\section{Sphere formation assay}

Sphere formation assay was performed based on the previously described method [31]. The ES-2 and OVCAR-3 cells were plated at different oxygen tensions for $48 \mathrm{hrs}$, and then dispatched from cell culture flask and harvested. Single cells (1000 cells per well) were re-plated and cultivated under normoxia at ultralow attachment six-well plates (ultra low cluster plates, Life sciences). These cells were cultivated for 14 days under normoxic condition before the spheres were evaluated under inverse miscopy and counted (more than 30 cells within a sphere was considered to be a full sphere). In addition, sphere formation assays of single CD44 $4^{\text {bright }}$ and CD44 ${ }^{\text {dim }}$ cells (800 cells per well) were also performed with the method as described above. All the experiments were repeated three times.

\section{Colony formation assay}

The cells in $80 \%$ confluent were cultivated in different oxygen conditions for $48 \mathrm{hrs}$ and then washed with PBS and dispatched from cell culture flask, harvested and counted with the Countess Cell Counter (Invitrogen). 500 cells/well were plated in 6-well plates and placed at $20 \%$ oxygen tension for 14 days, and the colonies were fixed with $4 \%$ buffered formalin for $15 \mathrm{~min}$ and then stained with $1 \%$ crystal violet for $30 \mathrm{~min}$. The plates were gently washed with PBS and dried before colony evaluation under microscopy. In addition, the CD44 $4^{\text {bright }}$ and CD44 ${ }^{\text {dim }}$ cells (500 cells/well) were also performed by colony formation assay with the method as described above. Colonies which contained more than 30 cells was counted. Colony formation efficiency was calculated as following: colony numbers/seed cells number $\times$ $100 \%$. Data are representative of three independent experiments.

\section{Flow cytometry and FACS}

After 48 hrs incubation under hypoxia $\left(1 \% \mathrm{O}_{2}\right)$ or normoxia $\left(20 \% \mathrm{O}_{2}\right)$, the cells were trypsinized, counted and washed with cold FACS buffer (PBS + BSA 0.02\%) with final concentration of $1 \times 10^{6}$ cells/tube. The cells were pre-blocked with $0.5 \%$ BSA for $30 \mathrm{~min}$ on ice before incubation for $30 \mathrm{~min}$ in the dark, on ice with CD44 monoclonal antibody directly conjugated with allophycoyanin (APC) and CD133 monoclonal antibody directly conjugated with fluorescein isothiocyanate (FITC) both obtained from BD Pharmingen Company. Following washing twice with ice-cold PBS, the cell suspensions in $800 \mu \mathrm{l}$ FACS buffer were filtered through a $70 \mathrm{~mm}$ nylon mesh. Samples were analyzed on a LSRII flow cytometer (Becton Dickinson, San Jose, CA, USA). Viable and single cells were gated for each sample acquired and APC Mouse IgG2b and FITC Mouse IgG2b (both from BD Pharmingen, USA) were used as negative control. The experiments were performed at three independent times. Data were analyzed using FlowJo software (Version 7.6).

For FACS, the cells were dissociated to viable single cell suspensions and stained with CD44 monoclonal antibody directly conjugated with APC as described above. Corresponding non-immune isotype was included as negative control. Top $10 \% \mathrm{CD}_{4} 4^{+}$were separated with FACS and determined as CD $44^{\text {bright }}$ cells and bottom $10 \%$ of CD $44^{-}$ cells were separated with FACS and determined as CD44 ${ }^{\text {dim }}$ cells. FACS was performed with a FACSAria flow cytometer (Becton Dickinson).

\section{SP analysis}

For SP analysis, $1 \times 10^{6}$ cells were suspended in pre-warmed RPMI 1640 medium containing 2\% fetal bovine serum and 2 mM HEPES buffer. Hoechst 33342 dye (Sigma-Aldrich) was added to a final concentration of $5 \mu \mathrm{g} / \mathrm{ml}$ from a stock solution of $1 \mathrm{mg} / \mathrm{ml}$ in presence or absence of verapamil (50 $\mu \mathrm{M}$; Sigma) and incubated at $37^{\circ} \mathrm{C}$ for $90 \mathrm{~min}$ with intermittent shaking. At the end of the incubation, the cells were washed with ice-cold HBSS with $2 \%$ FBS, centrifuged at $4{ }^{\circ} \mathrm{C}$ and re-suspended in ice-cold HBSS containing 2\% FBS. Propidium iodide at a final concentration of $2 \mu \mathrm{g} / \mathrm{ml}$ was added to the cells to gate viable cells. The cells were filtered through a $70-\mu \mathrm{m}$ cell strainer to obtain single cell suspension before analyzed with a LSRII flow cytometer (BD Biosciences, Franklin Lakes, NJ, USA). Cell aggregates were discarded from the analysis by doublet discrimination. SP cells were visualized or sorted by use of red (blue, 402-446 nm) vs blue (red, 650670) ultraviolet channels both in linear mode.

\section{Western blot analysis}

Cultured cells were harvested and lysed with $200 \mu \mathrm{l}$ of whole cell protein RIPA buffer ( $25 \mathrm{mM}$ Tris $\mathrm{HCl} \mathrm{pH} \mathrm{7.6,}$ $100 \mathrm{mM} \mathrm{NaCl}, 1 \%$ NP40, 1\% Sodium deoxycholate, 0.1\% SDS, Thermo Scientific Pierce, Bonn, Germany) with added freshly prepared proteinase inhibitors $(0.1 \mu \mathrm{M}$ Aprotinin, 1.0 mM PMSF, $1 \mu \mathrm{M}$ Leupeptin, $1 \mu \mathrm{M}$ Pepstatin), and then the samples were frozen at $-70{ }^{\circ} \mathrm{C}$ for $30 \mathrm{~min}$. The samples were centrifuged at 15,000 rpm for $15 \mathrm{~min}$ at $4{ }^{\circ} \mathrm{C}$ and the supernatants were transferred to new tubes. The protein concentrations were measured with Bio-Rad protein assay (Hercules, CA, USA) according to the manufacturer's instruction. After heated with a benchtop heater (Model 111002, Boekel Scientific, Feasterville, PA, USA) at $100{ }^{\circ} \mathrm{C}$ for $5 \mathrm{~min}$ in SDS-loading buffer $(500 \mathrm{mM}$ Tris $\mathrm{HCl} \mathrm{pH} \mathrm{6.8;} \mathrm{10 \%} \mathrm{Glycerol,} \mathrm{2 \%} \mathrm{SDS,}$ 0.6 M DTT, 0.05\% Bromphenol blue), $50 \mu \mathrm{g}$ protein per 
sample was subjected to 10\% SDS-PAGE and transferred to polyvinylidene difluoride transfer membrane (Bio-Rad). Membranes were blocked with $5 \%$ non-fat dry milk in 0.05\% TBS-Tween for $90 \mathrm{~min}$ at room temperature and incubated overnight at $4{ }^{\circ} \mathrm{C}$ with the primary antibodies against GAPDH $(0.2 \mu \mathrm{g} / \mathrm{ml})$, Oct3/4 $(1 \mu \mathrm{g} / \mathrm{ml})$, Sox2 $(1 \mu \mathrm{g} / \mathrm{ml}), \operatorname{HIF}-1 \alpha(1 \mu \mathrm{g} / \mathrm{ml})$ and HIF- $2 \alpha(1 \mu \mathrm{g} / \mathrm{ml})$ all from R\&D Systems, Minneapolis, MN, USA. The membranes were then incubated with corresponding secondary HRP-conjugated antibodies including anti-goat IgGHRP antibody (1:2000) or anti-mouse IgG-HRP antibody (1:1000) all from R\&D Systems, Minneapolis, MN, USA. Immuno-complexes were visualized by enhanced chemiluminescence (GE Healthcare, Bucks, and UK). The western blotting experiments were repeated at least three times.

\section{Statistical analyses}

Data are shown as mean \pm SEM of at least 3 experiments for each experiment. SPSS software (version 16.0) was used for data analysis. Statistical analysis was performed using Student's $T$ test $(P<0.05$ was considered statistically significant.

\section{Results}

Hypoxia results in comparatively slower growth rate with extended G0/G1 cell cycle

ES-2 and OVCAR-3 ovarian cancer cell lines were cultivated under either hypoxia or normoxia for periods of times by MTT assay to investigate the effect of hypoxia on cell growth. As shown in Figure 1A, the cells cultivated under $1 \% \mathrm{O}_{2}$ (hypoxia) grew relatively slowly than the cells cultivated under normoxia $(P<0.01)$, although the growth difference was not so apparent in the first 48 hrs, indicating that the cell growth was inhibited under hypoxic condition. The cells cultivated under either hypoxia or normoxia were then examined with cell cycle analysis. It could be repeatedly shown that there was significantly increasing number of G0/G1 phase cells in the OVCAR-3 and ES- 2 cells, from $50.8 \pm 6.2 \%$ and $53.17 \pm 1.98 \%$ in the cells cultivated under normoxia compared to $74.1 \pm 4.5 \%$

A
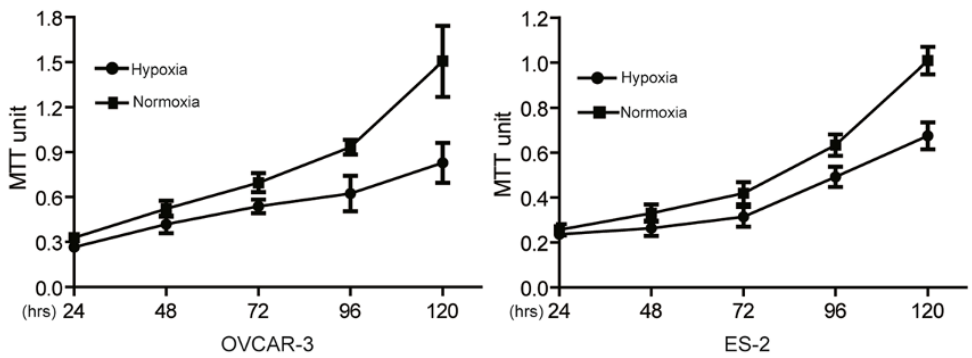

B

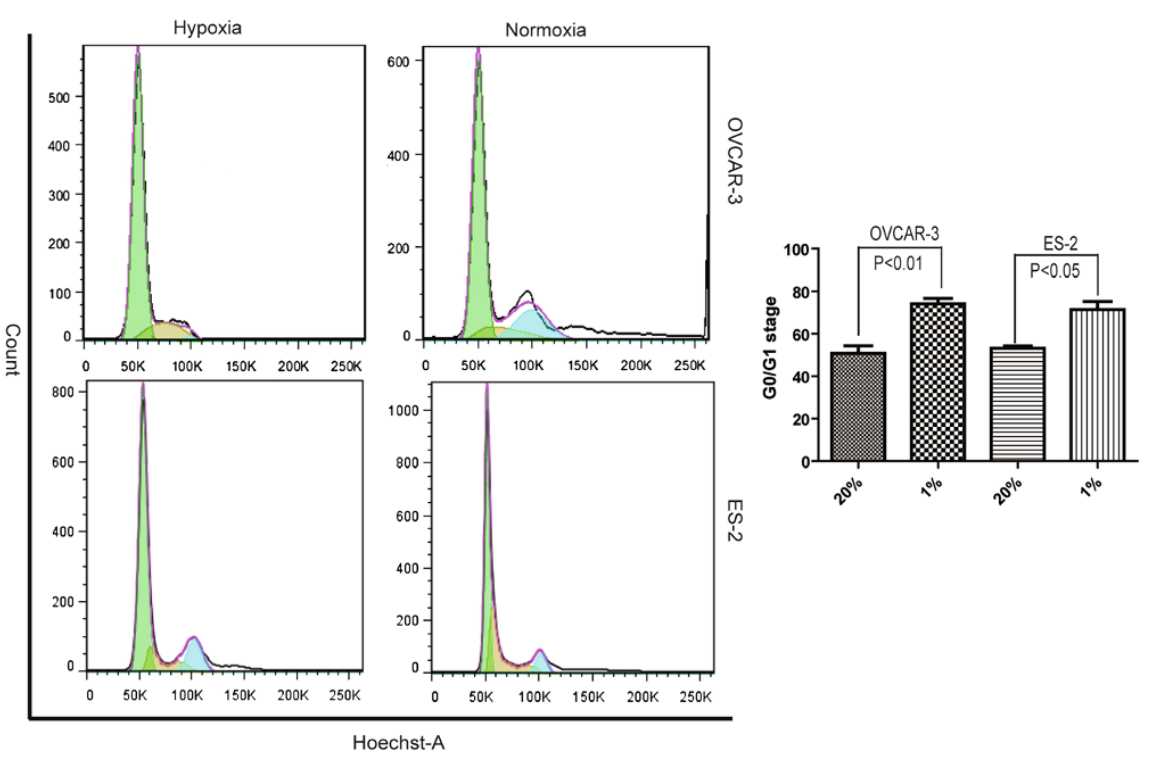

Figure 1 Hypoxia extended G0/G1 status with relatively slow growth of cells. Both OVCAR-3 and ES-2 cells were maintained under either hypoxia or normoxia for variable periods of times. (A) Growth curves show that the cells under hypoxia grew relatively slower than those cells under normoxia $(P<0.01)$. (B) Cell cycle analyses show extended $G 0 / G 1$ phase in the cells cultivated under hypoxia, and the corresponding histogram shows statistically significantly increased G0/G1 stage in both cell lines $(P<0.01$ for OVCAR-3 and $P<0.05$ for ES-2). 
and $71.44 \pm 6.6 \%$ in the cells cultivated under hypoxia, respectively (Figure 1B). As shown in the histogram, there was statistically significant difference for G0/G1 stage in both cell lines $(P<0.01$ for OVCAR-3 and $P<0.05$ for ES-2), indicating more quiescent cells under hypoxia condition.

\section{Hypoxic pretreatment promotes cell proliferation and invasion}

To explore how hypoxia-pretreatment influenced the biological behaviors of the cells, proliferation and invasion assays were performed. As shown in Figure 2A, all the hypoxia pretreated cells grow faster than those control cells always cultivated in normoxia. When the cells were pretreated under hypoxia for $48 \mathrm{hrs}$ and then cultivated under normoxia, MTT values of both cell lines were significantly higher than those cells always kept under normoxia $(P<0.05)$. Furthermore, our invasive assays revealed significantly higher number of invasive cells in the hypoxia pretreated cells, both in the OVCAR-3 and ES-2 cells. As shown in Figure 2B, there are 2.9-fold increase in number of invasive cells in the OVCAR-3 cells under hypoxia and 3.5-fold increase in number of invasive cells in the ES-2 cells under hypoxia $(P<0.0001$ for both cell lines).
Hypoxia increases sphere and colony formation capability of the cells

Under normoxia condition, spheres could be observed in both cell lines (Figure 3A). Comparatively, hypoxia pretreatment increased the number of spheres, with 1.96-fold increase in the VCAR-3 cells and 1.59-fold increase in the ES2 cells (Figure 3B). The cells with hypoxia pretreatment were also examined with the colony formation assay. Compared with the cells always kept in normoxia, more colonies were observed in the hypoxia pretreated cells (Figure 3C), with 2.38-fold increase in the OVCAR-3 cells and 2.86-fold increase in the ES-2 cells, respectively (Figure 3D).

\section{Hypoxia upregulates the expression of CD44 and CD133}

The surface markers CD44 and CD133 were examined by flow cytometry in consideration of the effect of hypoxia. There were 1.99-fold increase in CD44 expression in the OVCAR-3 cells under hypoxia and 2.73 fold increase in CD44 expression in the hypoxia cultivated ES-2 cells (Figure 4A). CD133 expression in the OVCAR-3 cells was also increased with 1.48-fold, while almost no change was observed in the ES-2 cells under hypoxia (Figure 4B). All these data indicate that hypoxia induces the expression of CD44 expression in these cell lines, and also positively

\section{A}
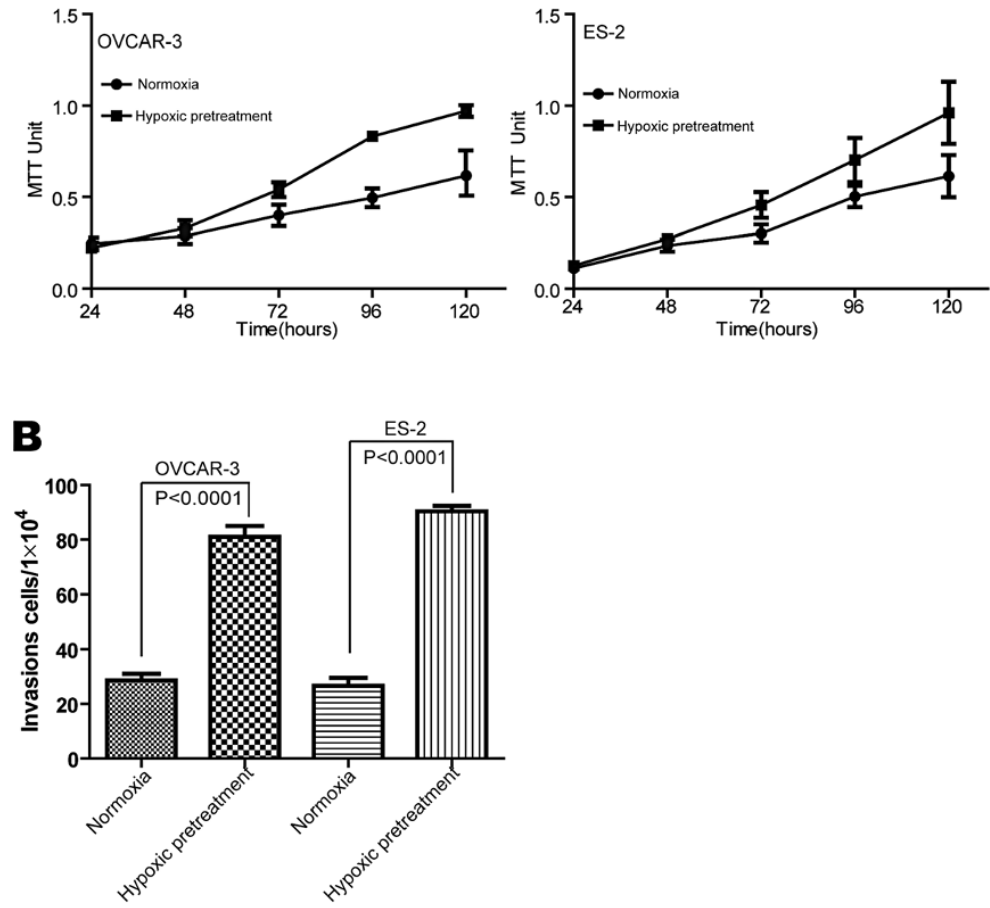

Figure 2 Hypoxia pretreatment induced cell proliferation and invasion potential. All the cells were cultivated under either hypoxia or normoxia for $48 \mathrm{hrs}$ before brought back to normoxia condition for proliferation or invasion assays. (A) The cells with hypoxia pretreatment for 48 hrs show significantly faster in growth than the cells always cultivated under normoxia $(P<0.05)$. (B) Cell invasion assays show that there are significantly more infiltrated cells in the hypoxia pretreated groups than those in the normoxia control groups in both cell lines $(P<0.0001)$. 
A
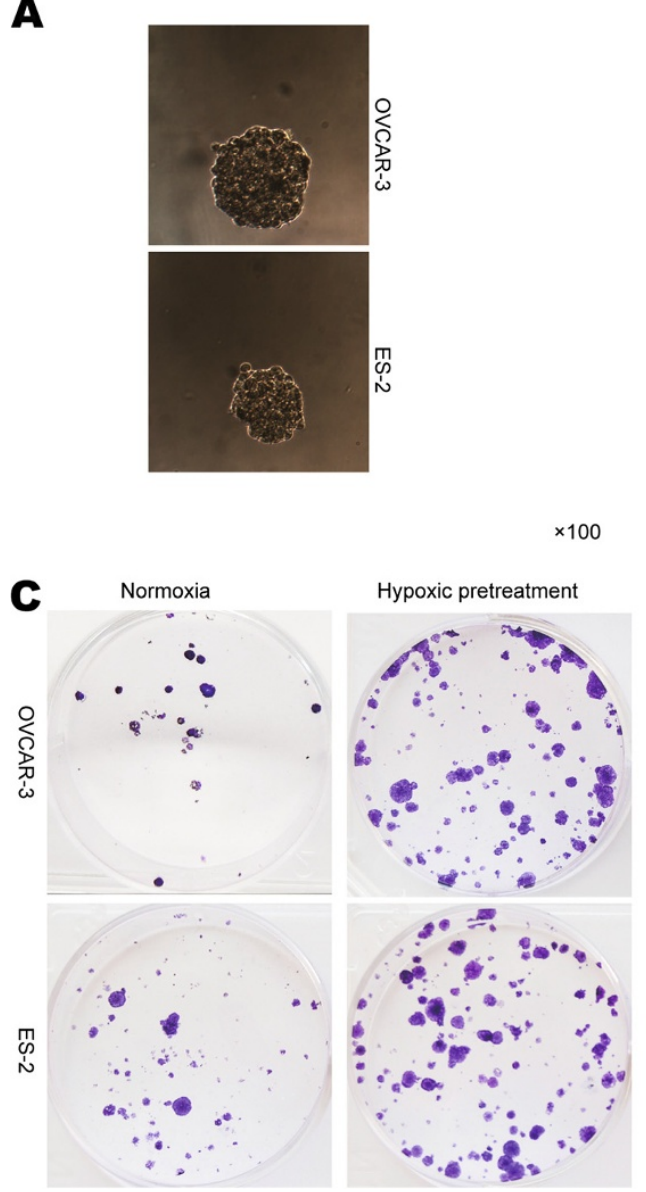

$\mathbf{B}$

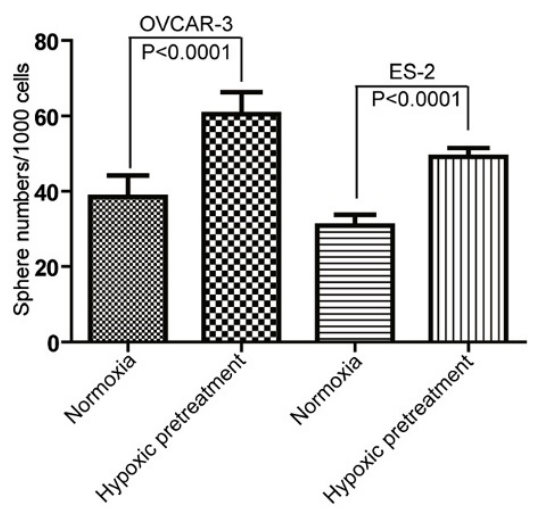

D

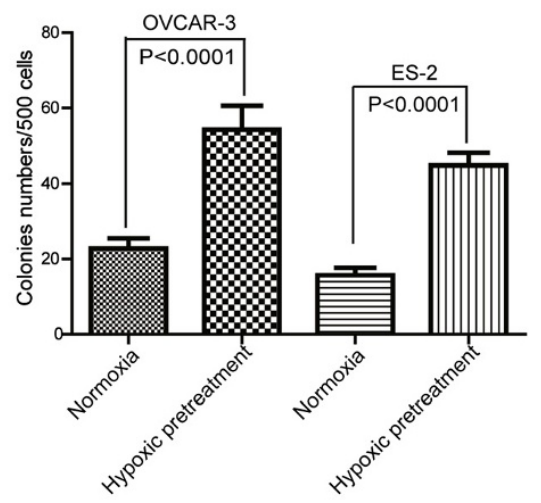

Figure 3 Hypoxia pretreatment increased the sphere and colony formation capability of cells. (A) Figure 3A shows representative spheres of the cells cultivated under normoxia. (B) Results from three independent experiments show significantly more spheres in the hypoxia pretreated groups than the control groups for both cell lines $(P<0.0001)$. (C) Colony formation assay shows more colonies in the hypoxia pretreated cells. (D) Results from three independent experiments show significantly more colonies in the hypoxia pre-treated groups than those in the normoxia controls $(P<0.0001)$.

influences the expression of CD133, at least in the OVCAR-3 cells.

\section{Hypoxia enriches SP cells}

To determine whether hypoxia affected stemness properties in ovarian cancer cells, the SP assay was performed in the ovarian cancer cell lines OVCAR-3 and ES-2 cells cultivated either under normoxia $\left(20 \% \mathrm{O}_{2}\right)$ or under hypoxia $\left(1 \% \mathrm{O}_{2}\right)$ for 48 hrs. As shown in Figure $4 \mathrm{C}$ hypoxia could enrich SP cells in both the OVCAR-3 and ES-2 cells, with about 7-fold increase in the hypoxia cultivated OVCAR-3 cells and 3.7fold increase in the hypoxia cultivated ES-2 cells, compared to the cells cultivated under normxia.

\section{Hypoxia up-regulates HIFs and transcription factors}

Hypoxia-inducible factors are a major family of transcriptional factors activated by hypoxia. The effect of hypoxia on the HIF- $1 \alpha$ and HIF- $2 \alpha$ expressions was investigated in the ovarian cancer cell lines. The expression of HIF- $1 \alpha$ and HIF$2 \alpha$ in both the OVCAR-3 and ES- 2 cells were significantly increased in the cells cultivated under hypoxia for $48 \mathrm{hrs}$, whereas the cells cultivated under normoxia for $48 \mathrm{hrs}$ were only weakly positive (Figure 4D). In the normoxia cultures the level of HIF- $2 \alpha$ was higher than the level of HIF- $1 \alpha$. The expression of both Oct $3 / 4$ and Sox 2 was significantly increased in the ES-2 and OVCAR-3 cells cultivated in the hypoxia condition for $48 \mathrm{hrs}$, in comparison to the cells cultivated in normoxia condition (Figure 4E).

\section{CD44 ${ }^{\text {bright }}$ cells display stem-like properties}

We discovered during our experiments that the SP cells separated by FACS were difficult to maintain in vitro, most probably due to the chemical damage of the Hoechst 33342 dye. In addition, the CD133 expression was not repeatedly 


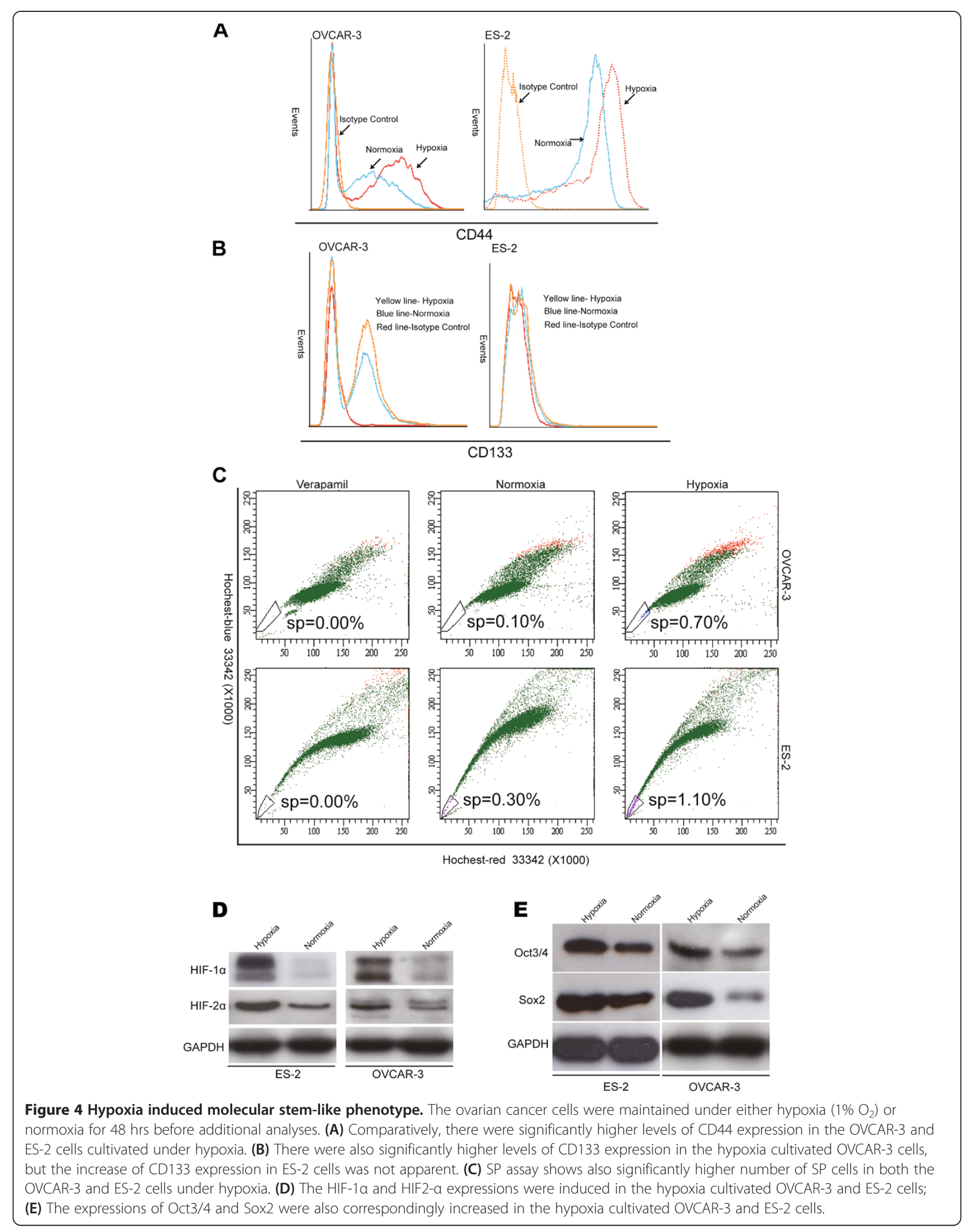


A

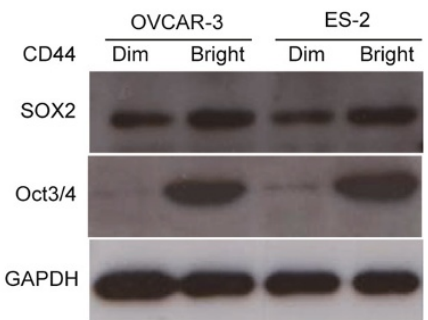

B
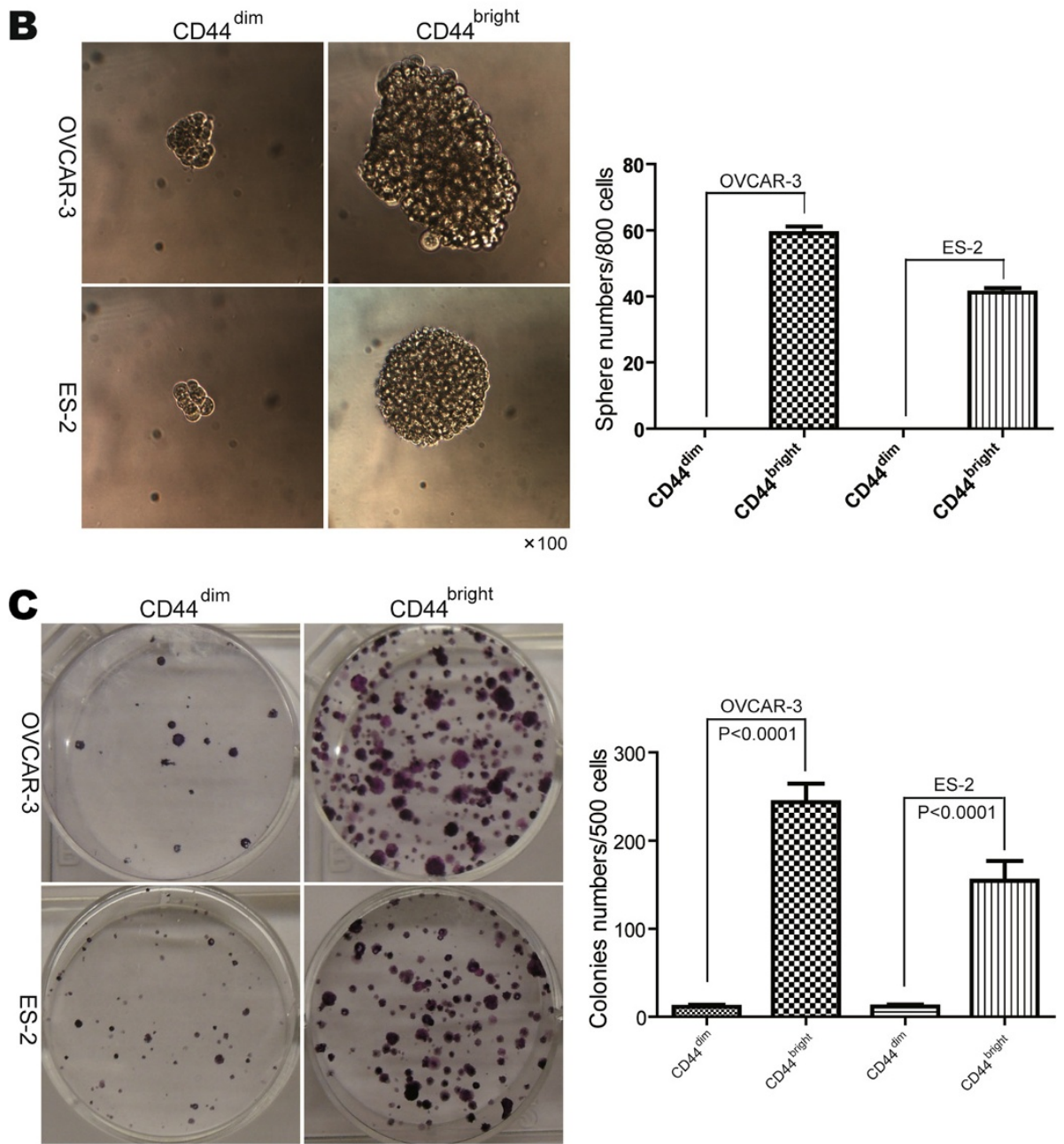

Figure 5 CD44 ${ }^{\text {bright }}$ cells show stem-like properties. The CD44 bright and CD44 ${ }^{\text {dim }}$ cells were sorted by FACS from the OVCAR-3 and ES-2 cells before additional Western blotting, sphere and colony formation assays. (A) The CD44 bright cells expressed higher levels of Sox2 and Oct3/4 than the CD44 ${ }^{\text {dim }}$ cells in both cell lines. (B) Larger spheres from the CD44 ${ }^{\text {bright }}$ cells and cell clusters not qualified as spheres from the CD44 ${ }^{\text {dim }}$ cells in both cell lines are shown (left panel) with a corresponding histogram (right panel). (C) Colony formation assay also shows more colonies in the CD44 ${ }^{\text {bright }}$ cells compared to the CD44 $4^{\text {dim }}$ cells in both cell lines (left panel). Three independent colony formation assays show statistically significantly more colonies in the CD44 $4^{\text {bright }}$ cells, in comparison to the CD44 ${ }^{\text {dim }}$ cells in both cell lines $(P<0.0001$, right panel).

elevated in the ES-2 cells under hypoxia. Therefore, we decided to further study the CD44 $4^{\text {bright }}$ cells in special consideration of their stemness features in vitro. As shown in Figure $5 \mathrm{~A}$, the $\mathrm{CD} 44^{\text {bright }}$ ovarian cancer cells expressed high levels of Oct3/4, whereas the CD44 ${ }^{\mathrm{dim}}$ cells expressed almost no Oct3/4 in both cell lines. The CD44 ${ }^{\text {bright }}$ cells expressed higher levels of Sox 2 than the CD44 ${ }^{\mathrm{dim}}$ cells.

In sphere formation assay, there was almost no qualified sphere in the $\mathrm{CD} 44^{\mathrm{dim}}$ cells, whereas more spheres were observed in the CD44 $4^{\text {bright }}$ cells (Figure $5 \mathrm{~A}$ and $\mathrm{B}$ ). In 
addition, significantly more colonies could be observed in the $\mathrm{CD} 44^{\text {bright }}$ cells than the $\mathrm{CD} 44^{\mathrm{dim}}$ cells examined with the method of colony formation assay (Figure $5 \mathrm{C}, P<0.0001$ ).

\section{Discussion}

Hypoxia is an inherent characteristic of many solid tumors. It is well known pathologically that tumor cells tolerate hypoxic environment. It has been documented in embryonic and adult stem cell research that hypoxia favors cell growth in vitro [32-35]. However for cancer cells, it is not fully studied how hypoxia influences the stem-like properties, although there has been a great progress in this field [18,36-39]. Therefore we explored whether hypoxia is a driving force for the growth of ovarian cancer cells in vitro by performing MTT experiment. It was found that although the growth difference was not apparent during the first $48 \mathrm{hrs}$, the cells in the hypoxic condition grew generally slower that the corresponding cells under normoxia. The cells cultivated under hypoxia were further investigated by cell cycle analysis. We discovered that both ES-2 and OVCAR-3 cell lines experienced a significant G0/G1 phase extension under hypoxia for $48 \mathrm{hrs,} \mathrm{indi-}$ cating more quiescent cells under hypoxia. This result is in line with other tumor cell studies [40-42]. Theoretically, cancer stem cells should have a low rate of division and proliferation in their niche which may help to decrease their chemotherapy and radiotherapy sensitivity $[3,8,38]$.

Then we focused on the effect of hypoxia pretreatment followed by normoxia cultivation in the ovarian tumor cell lines, since in present study we found that the cells grew poor if always placed under hypoxia. The tumor cells were placed under $1 \% \mathrm{O}_{2}$ for $48 \mathrm{hrs}$ as hypoxia pretreatment group before they were brought back to normoxia, with the cells always under normoxia as control. We found that the hypoxia pretreated tumor cells followed by normoxia cultivation grew significantly faster with significantly higher infiltration capability in comparison to the cells always in normoxia. These results indicate that cancer cells may switch into a more stem-like status when meeting with hypoxic stress, and develop more aggressive phenotype in a manner of selection in a suddenly higher oxygen environment, such as when tumor cells penetrate into blood stream or when the "dormant" metastatic solid tumor cells are mobilized out of bone marrow by till now un-clarified mechanisms. This may be useful to explain why hypoxia not only accounts for tissue necrosis, but also a strong impact on tumor cell biology, with a decreased sensitivity to apoptotic and other cell-death signals, and an increased signaling to promote angiogenesis, proliferation and systemic metastasis capacity when the niche permits [43-46].

It is known that cancer stem cells residing in epithelial ovarian cancers can be $\mathrm{CD} 133^{+}[24]$ or $\mathrm{CD} 44^{+}$subpopulation cells [26] and these specific markers may be potential therapeutic targets in this devastating disease. Therefore the influence of hypoxia on the expression of these two markers was explored in this study. Our results show that $48 \mathrm{hrs} 1 \% \mathrm{O}_{2}$ treatment could result in about 2.0-2.7-fold increase in CD44 expression in both ES-2 and OVCAR-3 cell lines, and about 1.5-fold increase in CD133 expression in the OVCAR-3 cell line. These results are supported by other reports that hypoxia helps to expand the $\mathrm{CD} 133^{+}$ pancreatic cancer cells [47] and CD133 ${ }^{+}$glioma stem cells [48]. It is also reported that hypoxia enriches the CD44 ${ }^{+} / \mathrm{CD} 24^{-}$breast cancer stem-like cells [49] and CD44 ${ }^{+}$ murine mesenchymal stem cells [47-50].

To study the effect of hypoxia on stem-like cell phenotypes, we assessed the fraction of SP cells since SP assay has been successfully used for identification of cancer stem-like cells in hepatocellular, breast and ovarian cancers $[14,23,29,51,52]$. We found that hypoxia could induce the SP subpopulation in both OVCAR-3 cells and ES-2 cells. In addition, the increased SP cells were in parallel with increasing expression levels of HIF- $1 \alpha$ and HIF- $2 \alpha$ in both cell lines. It is known that hypoxia often occurs inside solid tumor and exhibits more severe at the undifferentiated parts of tumors compared to surrounding tumor or normal tissues. The initial response of cancer cells to hypoxia is the activation of hypoxia responsive transcription factor. The hypoxia inducible factors HIF- $1 \alpha$ and HIF- $2 \alpha$ are important factors activated under hypoxia. It has been reported that HIF-1 $\alpha$ expression is increased in other ovarian cancer cell lines in response to hypoxia [42,53], which are largely in line with our present study. It has been observed that HIFs influence the phenotypes of tumors by regulating a number of target genes such as glucose transporters, glycolic enzyme, vascular endothelial cell growth and growth factors $[16,18,54]$.

The stem-like property impact of hypoxia may be exerted through transcriptional factors, such as Oct3/4 $[16,32]$ and Sox2 [55]. Oct3/4 and Sox2 are key players in a transcriptional network for maintenance of embryonic stem cell and primordial germ cells self-renewal. Several studies suggest a role for Oct $3 / 4$ and Sox 2 in sustaining stem-like property of adult somatic stem cells $[56,57]$. Our study verifies that both Oct $3 / 4$ and Sox 2 were weakly expressed in the OVCAR-3 and ES2 cell lines, and the expressions of these proteins were up-regulated upon hypoxia exposure. Furthermore, such increasing levels of Oct3/4 and Sox 2 expression were in parallel with the increasing levels of HIF- $1 \alpha$ and HIF- $2 \alpha$ expression under hypoxia. Previous study show that HIF- $2 \alpha$ binds to the promoter of Oct $3 / 4$ and directly induces its expression and activity [58], suggesting a potential role for the interaction of HIF- $2 \alpha$ and Oct3/4 in ovarian cancer cells upon hypoxia environment.

Since CD44 has been indicated as a putative surface marker for cancer stem/progenitor cells in breast and ovarian cancers $[23,26,27,49]$, and since its expression was 
significantly up-regulated in the OVCAR-3 and ES2 cell lines under hypoxia, we decided to further analyze whether CD44 expression was associated with any stem-like property in these cells. The expression of Oct $3 / 4$ in the $\mathrm{CD} 44^{\mathrm{dim}}$ cells was almost negative, while its expression in the corresponding $\mathrm{CD} 44^{\text {bright }}$ cells was dramatically increased. We performed additional colony formation and sphere formation assays with the isolated corresponding CD $44^{\text {dim }}$ and CD $44^{\text {bright }}$ cells by FACS. Significantly more spheres and colonies could be repeatedly seen in the CD44 $4^{\text {bright }}$ cells than those CD $44^{\text {dim }}$ cells. Therefore, our results verify that hypoxia significantly increases the expression of CD44, and CD44 ${ }^{\text {bright }}$ cells possess significantly higher stem-like properties in the ovarian cancer cell lines OVCAR-3 and ES2.

\section{Conclusion}

In summary, our results reveal that ovarian cancer cells OVCAR-3 and ES2 under hypoxia showed extended G0/G1 phase, a more quiescent status, and more SP cells. At the same time these cells under hypoxia expressed higher levels of CD44, CD133, Oct3/4 and Sox2. It is further verified that CD $44^{\text {bright }}$ cells contributed to the higher stem-like properties of the cells. If the cells were cultivated in $1 \% \mathrm{O}_{2}$ for $48 \mathrm{hrs}$ and then brought back to normoxia the cells demonstrated significantly higher growth rate with higher infiltration potential and significantly higher colony and sphere formation capability than those cells always under normoxia. It is concluded that ovarian cancer cells may survive hypoxia by upgrading their stem-like properties through up-regulation of stemness-related factors and behave more aggressively when brought back to higher oxygen environment.

\section{Competing interests}

The authors declare that there are no competing interests.

\section{Acknowledgments}

We are grateful to Idun Dale Rein and Kirsti Solberg Landsverk for assistance with flow cytometry and to The Norwegian Radium Hospital Legat and Inger and John Frederiksen Foundation for financial support.

\section{Author details \\ 'Departments of Pathology, the Norwegian Radium Hospital, Oslo University Hospital, University of Oslo, Montebello, Ullernchausseen 70, N-0310 Oslo, Norway. ${ }^{2}$ Departments of Gynaescology, the Norwegian Radium Hospital, Oslo University Hospital, University of Oslo, Montebello, Ullernchausseen 70, N-0310 Oslo, Norway. ${ }^{3}$ Departments of Pathology, Institute for Clinical Medicine, Faculty of Medicine, University of Oslo, Montebello, Ullernchausseen 70, N-0310 Oslo, Norway. ${ }^{4}$ Departments of Gynaecology, Institute for Clinical Medicine, Faculty of Medicine, University of Oslo, Montebello, Ullernchausseen 70, N-0310 Oslo, Norway. ${ }^{5}$ Department of Pathology, Basic Medical College, The First Teaching Hospital of Zhengzhou University, Zhengzhou University, Zhengzhou, Henan Province, China.}

\section{Authors' contributions}

$\mathrm{DL}$ carried out cell culture, MTT, colony formation and flow cytometry assays, analyzed the data and drafted the manuscript. YM performed cell culture, sphere formation and flow cytometry assays, analyzed the data and drafted the manuscript. JL performed the cell culture, western blotting experiments CGT, RH and JMN participated in the experiment design, analyzed the data and modified the manuscript.

ZS contributed to the design of the experiment, analysed the data and gave final approbal of the version to be submitted.

All the authors have read and approved the final manuscript.

Received: 26 October 2011 Accepted: 29 May 2012

Published: 29 May 2012

\section{References}

1. Higgins LH, Withers HG, Garbens A, Love HD, Magnoni L, Hayward SW, Moyes CD: Hypoxia and the metabolic phenotype of prostate cancer cells. Biochim Biophys Acta 2009, 1787(12):1433-1443.

2. Jensen RL: Brain tumor hypoxia: tumorigenesis, angiogenesis, imaging, pseudoprogression, and as a therapeutic target. J Neurooncol 2009, 92 (3):317-335.

3. Selvendiran K, Bratasz A, Kuppusamy ML, Tazi MF, Rivera BK, Kuppusamy P: Hypoxia induces chemoresistance in ovarian cancer cells by activation of signal transducer and activator of transcription 3. Int J Cancer 2009, 125(9):2198-2204.

4. Sooriakumaran $P$, Kaba R: Angiogenesis and the tumour hypoxia response in prostate cancer: a review. Int J Surg 2005, 3(1):61-67.

5. Vaupel $P$, Briest $S$, Hockel M: Hypoxia in breast cancer: pathogenesis, characterization and biological/therapeutic implications. Wien Med Wochenschr 2002, 152(13-14):334-342.

6. Majmundar AJ, Wong WJ, Simon MC: Hypoxia-inducible factors and the response to hypoxic stress. Mol Cell 2010, 40(2):294-309.

7. Kingsley LA, Fournier PG, Chirgwin JM, Guise TA: Molecular biology of bone metastasis. Mol Cancer Ther 2007, 6(10):2609-2617.

8. Feldmann $\mathrm{HJ}$ : Oxygenation of human tumors-implications for combined therapy. Lung Cancer 2001, 33(Suppl 1):S77-S83.

9. Kunz M, Ibrahim SM: Molecular responses to hypoxia in tumor cells. Mol Cancer 2003, 2:23.

10. Alvero AB, Fu HH, Holmberg J, Visintin I, Mor L, Marquina CC, Oidtman J, Silasi DA, Mor G: Stem-like ovarian cancer cells can serve as tumor vascular progenitors. Stem Cells 2009, 27(10):2405-2413.

11. Burkert J, Wright NA, Alison MR: Stem cells and cancer: an intimate relationship. J Pathol 2006, 209(3):287-297.

12. Conic I, Dimov I, Tasic-Dimov D, Djordjevic B, Stefanovic V: Ovarian epithelial cancer stem cells. Scientific World J 2011, 11:1243-1269.

13. Curley MD, Garrett LA, Schorge JO, Foster R, Rueda BR: Evidence for cancer stem cells contributing to the pathogenesis of ovarian cancer. Front Biosci 2011 16:368-392.

14. Gao Q, Geng L, Kvalheim G, Gaudernack G, Suo Z: Identification of cancer stem-like side population cells in ovarian cancer cell line OVCAR-3. Ultrastruct Pathol 2009, 33 (4):175-181.

15. Hjelmeland AB, Wu Q, Heddleston JM, Choudhary GS, MacSwords J, Lathia JD, McLendon R, Lindner D, Sloan A, Rich JN: Acidic stress promotes a glioma stem cell phenotype. Cell Death Differ 2011, 18(5):829-840.

16. Keith B, Simon MC: Hypoxia-inducible factors, stem cells, and cancer. Cell 2007, 129(3):465-472.

17. Mor G, Yin G, Chefetz I, Yang Y, Alvero A: Ovarian cancer stem cells and inflammation. Canc Biol Ther 2011, 11(8):708-713.

18. Heddleston JM, Li Z, Lathia JD, Bao S, Hjelmeland AB, Rich JN: Hypoxia inducible factors in cancer stem cells. Br J Cancer 2010, 102(5):789-795.

19. Rizzino A: Sox2 and Oct-3/4: a versatile pair of master regulators that orchestrate the self-renewal and pluripotency of embryonic stem cells. Wiley Interdiscip Rev Syst Biol Med 2009, 1(2):228-236.

20. Peng S, Maihle NJ, Huang Y: Pluripotency factors Lin28 and Oct4 identify a sub-population of stem cell-like cells in ovarian cancer. Oncogene 2010, 29(14):2153-2159.

21. Ben-Porath I, Thomson MW, Carey VJ, Ge R, Bell GW, Regev A, Weinberg RA: An embryonic stem cell-like gene expression signature in poorly differentiated aggressive human tumors. Nat Genet 2008, 40(5):499-507.

22. Curley MD, Therrien VA, Cummings CL, Sergent PA, Koulouris CR, Friel AM, Roberts DJ, Seiden MV, Scadden DT, Rueda BR, et al: CD133 expression defines a tumor initiating cell population in primary human ovarian cancer. Stem Cells 2009, 27(12):2875-2883.

23. Fong MY, Kakar SS: The role of cancer stem cells and the side population in epithelial ovarian cancer. Histol Histopathol 2011, 25(1):113-120. 
24. Kusumbe AP, Mali AM, Bapat SA: CD133-expressing stem cells associated with ovarian metastases establish an endothelial hierarchy and contribute to tumor vasculature. Stem Cells 2009, 27(3):498-508.

25. Liu T, Cheng W, Lai D, Huang Y, Guo L: Characterization of primary ovarian cancer cells in different culture systems. Oncol Rep 2010, 23(5):1277-1284.

26. Slomiany MG, Dai L, Tolliver LB, Grass GD, Zeng Y, Toole BP: Inhibition of Functional Hyaluronan-CD44 Interactions in CD133-positive Primary Human Ovarian Carcinoma Cells by Small Hyaluronan Oligosaccharides. Clin Cancer Res 2009, 15(24):7593-7601.

27. Cannistra SA, DeFranzo B, Niloff J, Ottensmeir C: Functional heterogeneity of CD44 molecules in ovarian cancer cell lines. Clin Cancer Res 1995, 1(3):333-342

28. Hu L, McArthur C, Jaffe RB: Ovarian cancer stem-like side-population cells are tumourigenic and chemoresistant. Br J Cancer 2010, 102(8):1276-1283.

29. Szotek PP, Pieretti-Vanmarcke R, Masiakos PT, Dinulescu DM, Connolly D, Foster R, Dombkowski D, Preffer F, Maclaughlin DT, Donahoe PK: Ovarian cancer side population defines cells with stem cell-like characteristics and Mullerian Inhibiting Substance responsiveness. Proc Natl Acad Sci USA 2006, 103(30):11154-11159.

30. Li Y, Bhuiyan M, Sarkar FH: Induction of apoptosis and inhibition of cerbB-2 in MDA-MB-435 cells by genistein. Int J Oncol 1999, 15(3):525-533.

31. Dontu G, Abdallah WM, Foley JM, Jackson KW, Clarke MF, Kawamura MJ, Wicha MS: In vitro propagation and transcriptional profiling of human mammary stem/progenitor cells. Genes Dev 2003, 17(10):1253-1270.

32. Ji L, Liu YX, Yang C, Yue W, Shi SS, Bai CX, Xi JF, Nan X, Pei XT: Self-renewal and pluripotency is maintained in human embryonic stem cells by coculture with human fetal liver stromal cells expressing hypoxia inducible factor 1alpha. J Cell Physiol 2009, 221(1):54-66.

33. Lee EY, Xia Y, Kim WS, Kim MH, Kim TH, Kim KJ, Park BS, Sung JH: Hypoxiaenhanced wound-healing function of adipose-derived stem cells: increase in stem cell proliferation and up-regulation of VEGF and bFGF. Wound Repair Regen 2009, 17(4):540-547.

34. Yoshida Y, Takahashi K, Okita K, Ichisaka T, Yamanaka S: Hypoxia enhances the generation of induced pluripotent stem cells. Cell Stem Cell 2009, 5 (3):237-241.

35. Zhao T, Zhang CP, Liu ZH, Wu LY, Huang X, Wu HT, Xiong L, Wang X, Wang $\mathrm{XM}$, Zhu LL, et al: Hypoxia-driven proliferation of embryonic neural stem/ progenitor cells-role of hypoxia-inducible transcription factor-1alpha. FEBS J 2008, 275(8):1824-1834.

36. Chen J, Imanaka N, Chen J, Griffin JD: Hypoxia potentiates Notch signaling in breast cancer leading to decreased E-cadherin expression and increased cell migration and invasion. Br J Cancer 2010, 102(2):351-360.

37. Denny WA: Hypoxia-activated prodrugs in cancer therapy: progress to the clinic. Future Oncol 2010, 6(3):419-428.

38. McCarty MF, Barroso-Aranda J, Contreras F: Practical strategies for suppressing hypoxia-inducible factor activity in cancer therapy. Med Hypotheses 2010, 74(5):789-797.

39. Semenza GL: Defining the role of hypoxia-inducible factor 1 in cancer biology and therapeutics. Oncogene 2010, 29(5):625-634.

40. Box AH, Demetrick DJ: Cell cycle kinase inhibitor expression and hypoxiainduced cell cycle arrest in human cancer cell lines. Carcinogenesis 2004, 25(12):2325-2335.

41. Yoshiba S, Ito D, Nagumo T, Shirota T, Hatori M, Shintani S: Hypoxia induces resistance to 5 -fluorouracil in oral cancer cells via $\mathrm{G}(1)$ phase cell cycle arrest. Oral Oncol 2009, 45(2):109-115.

42. Huang L, Ao Q, Zhang Q, Yang X, Xing H, Li F, Chen G, Zhou J, Wang S, Xu $G$, et al: Hypoxia induced paclitaxel resistance in human ovarian cancers via hypoxia-inducible factor 1alpha. J Cancer Res Clin Oncol 2010, 136 (3):447-456

43. De Bock K, Mazzone M, Carmeliet P: Antiangiogenic therapy, hypoxia, and metastasis: risky liaisons, or not? Nat Rev Clin Oncol 2011, 8(7):393-404.

44. Henze AT, Acker T: Feedback regulators of hypoxia-inducible factors and their role in cancer biology. Cell Cycle 2010, 9(14):2749-2763.

45. Cannito S, Novo E, Compagnone A, Valfre di Bonzo L, Busletta C, Zamara E, Paternostro C, Povero D, Bandino A, Bozzo F, et al: Redox mechanisms switch on hypoxia-dependent epithelial-mesenchymal transition in cancer cells. Carcinogenesis 2008, 29(12):2267-2278.

46. Gort EH, Groot AJ, van der Wall E, van Diest PJ, Vooijs MA: Hypoxic regulation of metastasis via hypoxia-inducible factors. Curr Mol Med 2008, 8(1):60-67.

47. Hashimoto O, Shimizu K, Semba S, Chiba S, Ku Y, Yokozaki H, Hori Y: Hypoxia Induces Tumor Aggressiveness and the Expansion of CD133-
Positive Cells in a Hypoxia-Inducible Factor-1alpha-Dependent Manner in Pancreatic Cancer Cells. Pathobiology 2011, 78(4):181-192.

48. Soeda A, Park M, Lee D, Mintz A, Androutsellis-Theotokis A, McKay RD, Engh J, Iwama T, Kunisada T, Kassam AB, et al: Hypoxia promotes expansion of the CD133-positive glioma stem cells through activation of HIF-1alpha. Oncogene 2009, 28(45):3949-3959.

49. Louie E, Nik S, Chen JS, Schmidt M, Song B, Pacson C, Chen XF, Park S, Ju J, Chen El: Identification of a stem-like cell population by exposing metastatic breast cancer cell lines to repetitive cycles of hypoxia and reoxygenation. Breast Canc Res 2010, 12(6):R94.

50. Valorani MG, Germani A, Otto WR, Harper L, Biddle A, Khoo CP, Lin WR Hawa MI, Tropel P, Patrizi MP, et al: Hypoxia increases Sca-1/CD44 coexpression in murine mesenchymal stem cells and enhances their adipogenic differentiation potential. Cell Tissue Res 2010, 341(1):111-120.

51. Chiba T, Kita K, Zheng YW, Yokosuka O, Saisho H, Iwama A, Nakauchi H, Taniguchi H: Side population purified from hepatocellular carcinoma cells harbors cancer stem cell-like properties. Hepatology 2006, 44(1):240-251.

52. Hiraga $T$, Ito $S$, Nakamura $H$ : Side population in MDA-MB-231 human breast cancer cells exhibits cancer stem cell-like properties without higher bone-metastatic potential. Oncol Rep 2011, 25(1):289-296.

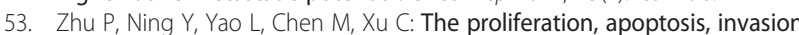
of endothelial-like epithelial ovarian cancer cells induced by hypoxia. $J$ Exp Clin Cancer Res 2010, 29:124.

54. Pescador N, Villar D, Cifuentes D, Garcia-Rocha M, Ortiz-Barahona A, Vazquez S, Ordonez A, Cuevas Y, Saez-Morales D, Garcia-Bermejo ML, et al: Hypoxia promotes glycogen accumulation through hypoxia inducible factor (HIF)-mediated induction of glycogen synthase 1. PLoS One 2010, 5(3): e9644.

55. Kolenda J, Jensen SS, Aaberg-Jessen C, Christensen K, Andersen C, Brunner $\mathrm{N}$, Kristensen BW: Effects of hypoxia on expression of a panel of stem cell and chemoresistance markers in glioblastoma-derived spheroids. $J$ Neurooncol 2011, 103(1):43-58.

56. Davis SF, Hood J, Thomas A, Bunnell BA: Isolation of adult rhesus neural stem and progenitor cells and differentiation into immature oligodendrocytes. Stem Cells Dev 2006, 15(2):191-199.

57. Tai MH, Chang CC, Kiupel M, Webster JD, Olson LK, Trosko JE: Oct4 expression in adult human stem cells: evidence in support of the stem cell theory of carcinogenesis. Carcinogenesis 2005, 26(2):495-502.

58. Covello KL, Kehler J, Yu H, Gordan JD, Arsham AM, Hu CJ, Labosky PA, Simon MC, Keith B: HIF-2alpha regulates Oct-4: effects of hypoxia on stem cell function, embryonic development, and tumor growth. Genes Dev 2006, 20(5):557-570.

doi:10.1186/1471-2407-12-201

Cite this article as: Liang et al:: The hypoxic microenvironment upgrades stem-like properties of ovarian cancer cells. BMC Cancer 2012 12:201.

\section{Submit your next manuscript to BioMed Central and take full advantage of:}

- Convenient online submission

- Thorough peer review

- No space constraints or color figure charges

- Immediate publication on acceptance

- Inclusion in PubMed, CAS, Scopus and Google Scholar

- Research which is freely available for redistribution 